\title{
Outcome after severe head injury treated by an integrated trauma system
}

\author{
T J Coats, C J C Kirk, M Dawson
}

\begin{abstract}
Objectives-To describe outcome after treatment of severe head injury within an integrated trauma system.

Methods-A retrospective analysis of all patients with severe head injury admitted to the Royal London Hospital by the Helicopter Emergency Medical Service (HEMS) between 1991 and 1994. Type of injury was defined on initial computed tomography of the head and outcomes assessed 12 months after injury using the Glasgow outcome score.

Results- $6.5 \%$ of HEMS patients had long term severe disability (severe disability or persistent vegetative state on the outcome score); $34.5 \%$ made a good recovery.

Conclusions-The concern that a large number of severely disabled long term survivors might result as a consequence of this system of trauma management is not confirmed. The case $\mathrm{mix}$ of severity of extracranial injuries in these patients makes comparison with other published series difficult, but these data fit the hypothesis that pre-hospital correction of hypoxia and hypotension after head injury improves outcome.

(F Accid Emerg Med 1999;16:182-185)
\end{abstract}

Keywords: emergency medical systems; head injury; outcomes

Patients with significant head injury are adversely affected by both abnormal physiology ${ }^{12}$ and delay between injury and specialist intervention. ${ }^{34}$ These patients have anatomical injuries that can be accurately defined on the basis of appearances on computed tomography of the head, ${ }^{5}$ and present a measurable range of disability after rehabilitation. ${ }^{6}$ This gives a clear indication of the effect of a system of trauma management.

The Royal London Helicopter Emergency

Helicopter Emergency Medical Service, Royal Hospitals Trust, Whitechapel, London

T J Coats

C J C Kirk

M Dawson

Correspondence to Mr T J Coats, Senior Lecturer in Accident and Emergency/Pre-hospital Care, Accident and Emergency Department, Royal London Hospital, Whitechapel, London E1 1BB (e-mail:

t.j.coats@mds.qmw.ac.uk).

Accepted 10 December 1998 shown to be associated with a trend towards an increase in survival of severely injured patients. ${ }^{11}$ The effect on disability in the head injured patient has not been assessed.

There is some concern that early intensive treatment after injury saves lives, but at the expense of increased severe disability or persistent vegetative state. Such long term disability would have a profoundly negative effect on any cost-benefit analysis. This study was performed to assess disability in patients treated by the HEMS after severe head injury.

\section{Methods}

All patients with severe head injuries admitted to the Royal London Hospital by the HEMS between 1 October 1991 and 31 December 1994 were included in the study. Severe head injury was defined as an initial Glasgow coma score(GCS) ${ }^{12}$ of $\leqslant 8$ in the first 24 hours after injury with an abbreviated injury score ${ }^{13}$ in the "head" area of $\geqslant 3$. Patients who did not have computed tomography of the head and preschool children (in whom outcome is difficult to categorise) were excluded.

Pre-hospital data was collected on the day of admission and recorded on paper (1991 and 1992) or directly into a computerised database (after 1992). Age, sex, and initial GCS were recorded. On discharge the patient's hospital notes were examined and data extracted about the in-hospital phase. The abbreviated injury score ${ }^{13}$ for each body area was recorded and the injury severity score ${ }^{14}$ calculated. Computed tomograms of the head were assessed by a neuroradiologist and classified according to the system derived from the Traumatic Coma Data Bank ${ }^{5}$ as shown in table 1.

The outcomes of all patients were assessed by a research physiotherapist trained in disability scoring, using the Glasgow outcome score. ${ }^{6}$ The score was determined using the patient's notes and telephone follow up. Wherever possible both the patient and a carer were interviewed.

\section{Results}

Two hundred and sixteen patients were included in the study. The median age was 31 years with interquartile range of 20-62 years (fig 1). Most were severely injured with a median injury severity score of 26 , interquartile range $20-36$ (fig 2). The distribution of lowest GCS in the first 24 hours is shown in fig 3. The distributions of extracranial injuries are shown in fig 4 . One hundred and ninety seven $(91 \%)$ of the patients were given an anaesthetic, intubated, and ventilated as part of prehospital resuscitation.

Table 1 Classification of computed tomography appearance in patients with a Glasgow coma score of $\leqslant 8$
No visible intracranial pathology on

$\begin{array}{ll}\text { Diffuse II } & \text { Cisterns present; midline shift } 0 \mathrm{~mm} \text { to } \\ & 5 \mathrm{~mm} \text {; no mass }>25 \mathrm{ml} \\ \text { Diffuse III } & \text { Cisterns compressed/absent; shift }<5\end{array}$

$\begin{array}{ll}\text { Diffuse II } & \text { Cisterns present; midline shift } 0 \mathrm{~mm} \\ & 5 \mathrm{~mm} \text {; no mass }>25 \mathrm{ml} \\ \text { Diffuse III } & \text { Cisterns compressed/absent; shift }<5\end{array}$ $\mathrm{mm}$; no mass $>25 \mathrm{ml}$

Diffuse IV Midline shift $>5 \mathrm{~mm}$; no mass $>25 \mathrm{ml}$ Any haematoma $>25 \mathrm{ml}$ (subdivided into evacuated or non-evacuated) computed tomography 


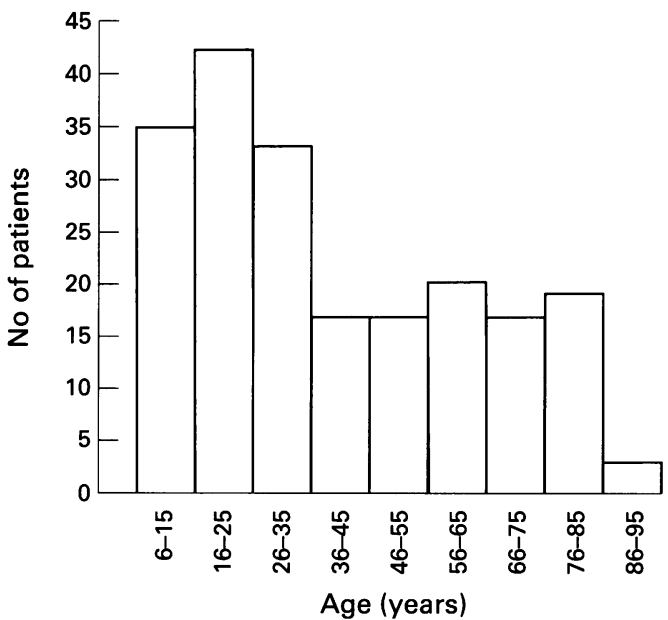

Figure 1 Age distribution of patients.

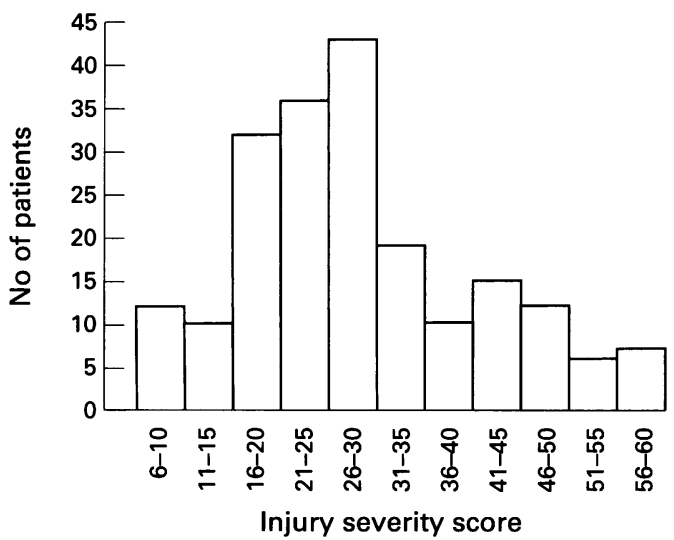

Figure 2 Distribution of injury severity scores.

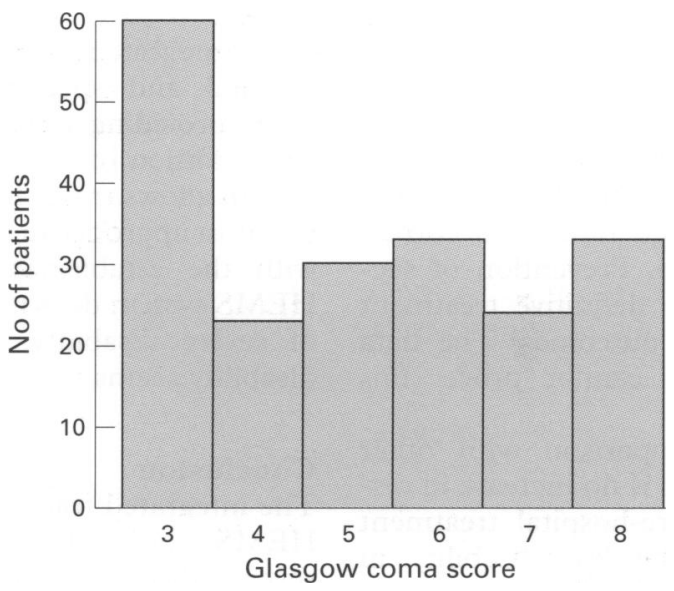

Figure 3 Distribution of Glasgow coma score.

As expected this severely injured group had a high mortality, with 108 (50\%) deaths. Nineteen of the survivors were lost to follow up (resident outside UK, moved, or declined), so $197(91 \%)$ patients could be classified on the Glasgow outcome scale (table 2). Follow up was performed at a median of 12 months after injury in survivors, with 14 patients being followed up for less than one year. Forty four (20.4\%) patients made a good recovery (resuming normal work and social activities), $31(14.0 \%)$ were left with moderate disability (independent but disabled), $13(6.0 \%)$ were severely disabled (conscious but disabled), and one $(0.5 \%)$ was in a persistent vegetative state (no evidence of meaningful response).
Table 2 Outcome of severe head injury from the Helicopter Emergency Medical Service (HEMS) and the Traumatic Coma Data Bank (TCDB)

\begin{tabular}{lll}
\hline Glasgow outcome scale & $\begin{array}{l}\text { No (\%) of } \\
\text { HEMS patients }\end{array}$ & $\begin{array}{l}\% \text { Of } \\
\text { TCDB patients }\end{array}$ \\
\hline Good recovery & $44(20.3)$ & 27 \\
Moderate disability & $31(14.2)$ & 16 \\
Severely disabled & $13(6.0)$ & 16 \\
Persistent vegetative state & $1(0.5)$ & 5 \\
Dead & $108(50.0)$ & 36 \\
Lost to follow up (alive) & $19(9.0)$ & 1 \\
\hline
\end{tabular}

Table 3 Outcome of severe head injury in the Helicopter Emergency Medical Service system by computed tomography classification

\begin{tabular}{lllll}
\hline & $\begin{array}{l}\text { Good } \\
\text { outcome }\end{array}$ & $\begin{array}{l}\text { Poor } \\
\text { outcome }\end{array}$ & Died & $\begin{array}{l}\text { Unknown } \\
\text { (but } \\
\text { survived) }\end{array}$ \\
\hline Diffuse I & 19 & 2 & 5 & 1 \\
Diffuse II & 16 & 5 & 14 & 2 \\
Diffuse III & 10 & 1 & 20 & 3 \\
Diffuse IV & 2 & 0 & 12 & 0 \\
$\quad$ Evacuated & 5 & 0 & 4 & 0 \\
$\quad$ extradural & 5 & 0 & 20 & 2 \\
$\begin{array}{l}\text { Evacuated subdural } \\
\text { Combination }\end{array}$ & 1 & 1 & 3 & 0 \\
Non-evacuated & 0 & & & \\
$\quad$ haematoma & 2 & 0 & 5 & 0 \\
$\quad$ Unknown & 20 & 5 & 25 & 11 \\
Total & 75 & 14 & 108 & 19 \\
\hline & & & &
\end{tabular}

Information was available to classify 155 $(72 \%)$ of the patients on the basis of their computed tomograms. The outcomes in head injury subgroups are shown in table 3. A good outcome was defined as either good recovery or a moderate disability as most of these patients return to productive social and economic lives, and a poor outcome as severe disability or persistent vegetative state.

\section{Discussion}

This study defines the amount of long term disability after early intensive pre-hospital treatment and early specialist intervention in an integrated trauma system. Previous studies have shown larger amounts of severe disability in similar patients. The most extensive set of head injury outcome data is that accumulated in the Traumatic Coma Data Bank. ${ }^{3}$ The overall outcomes from this database are shown in table 1. The Traumatic Coma Data Bank is not derived from an integrated trauma system, outcome data being submitted by neurosurgical tertiary referral centres. Patients who do not survive long enough to undergo an interhospital transfer are therefore excluded from the data bank but are included in this study of the HEMS system. The case mix of severity of extracranial injury is therefore likely to be different in these databases.

In the present series there may seem to be a large number of deaths compared with previous data. However the HEMS system is designed to select patients with severe multiple injuries (as shown by the distribution of injury severity scores) who would be expected to have a high mortality. A previous study showed that, within wide confidence intervals, the HEMS trauma system was associated with 13 additional survivors per year in patients with major injury. ${ }^{11}$ The same study found no increase in mortality in head injured patients once adjust- 

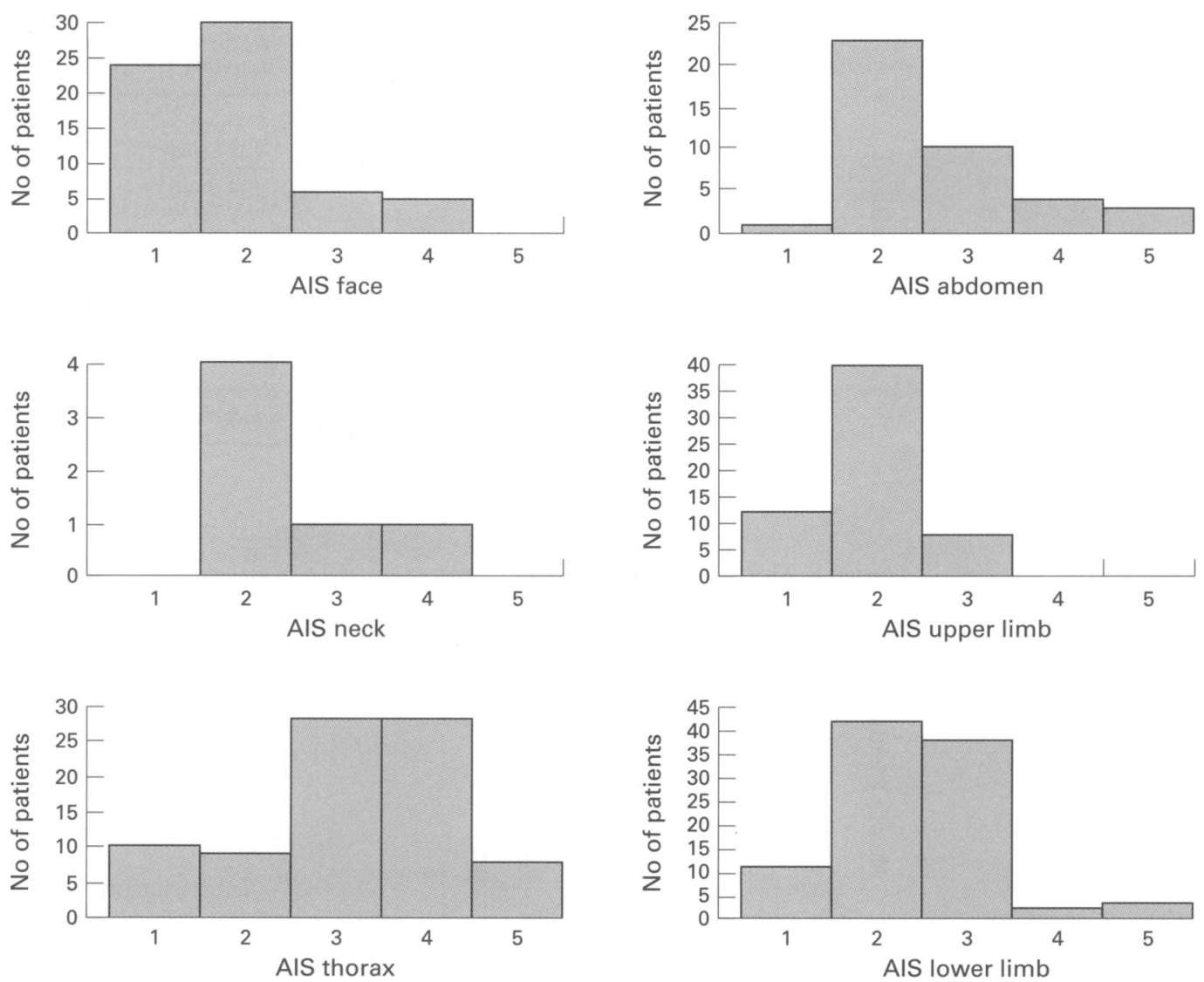

Figure 4 Distribution of extracranial injuries ( $A I S=$ abbreviated injury score).

ment had been made for other (extracranial) injuries, ${ }^{11}$ although very small numbers were studied. A significant improvement in outcome has been found in comparison with data collected by the UK Trauma Audit and Research Network..$^{15} 16$

The relationship between secondary insults to the injured brain and poor outcome are well known. ${ }^{12}{ }^{17-25}$ Treatment by the Royal London HEMS system is designed rapidly to correct hypotension and hypoxia. Prevention of secondary insults and early definitive treatment ought to lead to better outcomes. The data presented fit with, but cannot prove, this hypothesis.

Although further comparison with other datasets is required, there is no increase in disability with advanced pre-hospital treatment and there appears to be less disability in patients treated in this way. The moral and economic questions that would be raised by saving lives, but producing severe long term disability, are therefore avoided.

Long term severe disability has profound personal, social, and economic costs. Leaving aside personal costs, the amount of disability after head injury has a profound impact on the economic analysis of trauma systems. Each severely disabled survivor costs almost $£ 1000000$ for a lifetime of care (assuming a life expectancy of 25 to 30 years and a cost of approximately $£ 30000$ per year). For both humanitarian and economic reasons prevention of disability becomes an important objective. It also follows that any analysis of the benefit of a trauma system that does not include measures of disability is fatally flawed, as the cost of a single survivor with long term disability is approximately equal to the extra annual cost of the whole HEMS system to the health service.

An integrated trauma system combines prehospital and specialist in-hospital management, providing a seamless continuum of care. The addition of helicopter transport to such a system allows triage from the incident scene to the most appropriate hospital. When compared with the established medical literature the HEMS system does not seem to have an excess of severe disability, in fact the amount of disability seems to be lower than expected.

\section{Conclusion}

The integrated trauma system provided by the HEMS does not produce large numbers of severely disabled survivors. In comparison with previous series there seems to be a low rate of long term severe disability. As disability after injury has such a profound effect on health costs there is an urgent need for comparative studies to examine the effect of integration of advanced pre-hospital care with early definitive intervention on outcome after heat injury.

Conflict of interest: none.

Funding: none.

1 Miller JD, Becker DP. Secondary insults to the injured brain. $\mathcal{F} R$ Coll Surg Edinb 1982;27:292-8.

2 Chesnut RM, Marshall LF, Klauber MR, et al. The role of secondary brain injury in determining outcome from severe head injury. $\mathcal{F}$ Trauma 1993;34:216-22.

3 Marshall LF, Gauhlle T, Klauber MR, et al. The outcome of severe closed head injury. $\mathcal{F}$ Neurosurg 1991;75:S28-36.

4 Poon WS, Li AKC. Comparison of management outcome of primary and secondary referred patients with traumatic extradural haematoma in a neurosurgical unit. Injury 1991;
22:323-5. 
5 Marshall LF, Bowers-Marshall S, Klauber MR, et al. A new classification of head injury based on computerised tomography. $\mathcal{f}$ Neurosurg 1991;75:S14-20.

6 Jennett B, Snoek J, Bond MR, et al. Disability after severe head injury: observations on the use of the Glasgow outcome scale. $\mathcal{F}$ Neurol Neurosurg Psychiatry 1981;44:285-93.

scale. $\mathcal{J}$ Neurol Neurosurg Psychiatry 1981;44:285-93.
7 Kirk C, Earlam R, Wilson A, et al. Helicopter Emergency Kirk C, Earlam R, Wilson A, et al. Helicopter Emergency Medical Service operating from the Royal
Hospital: the first year. $B r \mathcal{F}$ Surg 1993;80:218-21.

Hospital: the first year. Br f Surg 1993;80:218-21.
8 Botha AJ, Earlam RJ, Wilson AW, et al. The Royal London Hospital Helicopter Emergency Medical Service: first phase 1990. f R Coll Surg Eng 1992;74(5 suppl):130-4.

9 Earlam R, ed. Trauma care-HEMS London. Colchester: Saldatore, 1997.

10 Wright K, Knowles C, Coats T, et al. "Efficient" timely evacuation of intracranial haematoma-the effect of transport direct to a specialist centre. Injury 1997;27:719-21.

11 Nicholl JP, Brazier JE, Snooks HA. Effects of London helicopter emergency medical service on survival after trauma. BMF 1995;311:217-22.

12 Teasdale G, Jennett B. Assessment of coma and impaired consciousness. A practical scale. Lancet 1974 ;ii:81-3.

13 Committee on Medical Aspects of Automotive Safety. Rating the severity of tissue damage II. The comprehensive ing the severity of tissue dama
scale. $¥ A M A$ 1972;220:717-20.

14 Baker SP, O'Neill B, Haddon W, et al. The injury severity score: a method for describing patients with multiple injuries score: a method for describing patients with multiple injuries

15 Younge $\mathrm{P}$, Coats T, Gurney D, et al. Using TRISS to measure the performance of the Helicopter Emergency Medical Service (HEMS) trauma system in groups with differen probabilities of survival. $\mathcal{F}$ Accid Emerg Med 1995;12:75.
16 Younge $\mathrm{P}$, Coats $\mathrm{T}$, Gurney $\mathrm{D}$, et al. Interpretation of the Ws statistic: application to an integrated trauma system. $\mathcal{F}$ Trauma 1997;43:511-15.

17 Gildenberg P, Makela $M$. Effect of early intubation and ventilation on outcome following head injury. In: Dacey $R$, ed. Trauma of the central nervous system. New York: Raven Press, 1985.

18 Ishige N, Pitts LH, Hashimoto T, et al. Effect of hypoxia on traumatic brain injury in rats: part 1. Changes in neurological function, electroencephalograms, and histopathology. Neurosurgery 1987;20:848-53.

19 Kohi YM, Mendelow AD, Teasdale GM, et al. Extra cranial insults and outcome in patients with acute head injury-relationship to the Glasgow coma scale. Injury 1984;16:25-9.

20 Maciver IN, Frew IJC, Matheson JG. The role of respiratory insufficiency in the mortality of severe head injuries. Lancet $1958 ; \mathbf{i}: 390-3$.

21 Miller JD, Sweet RC, Narayan R, et al. Early insults to the injured brain. $\mathcal{F A M A}$ 1978;240:439-42.

22 Miller JD. Head injury and brain ischaemia-implications for therapy. $B r \mathcal{F}$ Anaesth 1985;57:120-9.

23 Pietropaoli JA, Rogers FB, Shackford SR, et al. The deleterious effects of intraoperative hypotension on outcome in patients with severe head injuries. F Trauma 1992;33:403-7.

24 Price DJE, Murray A. The influence of hypoxia and hypotension on recovery from head injury. Injury 1972;3: 218-224.

25 Rose J, Valtone S, Jennett B. Avoidable factors contributing to death after head injury. $B M \mathcal{F} 1977 ; \mathrm{ii}: 615-18$. 